\title{
Transfer of oddity learning in the pigeon
}

\author{
RICHARD PISACRETA, PAUL LEFAVE, TIM LESNESKI, and CATHY POTTER \\ Ferris State College, Big Rapids, Michigan
}

\begin{abstract}
Two pigeons were trained on a six-key modified oddity-from-sample procedure. The stimuli were color pictures of birds, butterflies, and human faces. Initially, the third peck on the sample key (which presented one of three different bird pictures) lit only one comparison key. Every three additional pecks on the sample illuminated another comparison key. Fifteen sample pecks produced the maximum of five comparison stimuli. A peck on the comparison key that presented the nonmatching bird picture produced grain. Pecks on matching keys turned off all the comparison keys and repeated the trial. The birds learned to peck each sample until the nonmatching comparison stimulus was produced, and then to peck that key. After acquisition (70\%-90\% accuracy), the three bird stimuli were replaced by a new set of three bird pictures. Subsequent phases provided new sets of bird, butterfly, and human face stimuli. Both birds showed transfer of oddity learning to the novel samples. The data suggest that the birds may have been engaging in conceptualtype oddity learning, rather than learning discrete five-key discriminations or a series of two component chains.
\end{abstract}

The oddity-from-sample procedure (OFS) is frequently used as a technique for assessing conceptual abilities in nonhumans (Berryman, Cumming, Cohen, \& Johnson, 1965). We refer to concept learning as behavior that suggests that the animal has learned some rudimentary abstract "rule" involving same/different judgments. That is, the animal's behavior is controlled by conditional relationships between stimuli rather than by their absolute values. Hence, if the animal has learned more than discrete responses to particular stimulus conditions, it would be expected to (1) perform above chance when presented with novel oddity problems, and (2) require fewer sessions to reestablish asymptotic accuracy levels with new sets of oddity problems, relative to its performance with the original training stimuli.

After three decades of research, there is still no firm consensus as to whether pigeons can learn to engage in conceptual-type oddity behavior (e.g., Carter \& Werner, 1978; Lombardi, Fachinelli, \& Delius, 1984; Mackintosh, 1983; Macphail, 1982; Premack, 1978; Zentall, Hogan, Edwards, \& Hearst, 1980). Several investigators have modified the matching-to-sample (MTS) and OFS procedures, and have reported some degree of matching transfer (facilitated acquisition) to novel samples. Urcuioli and Nevin (1975) presented birds with a yellow, green, or red sample on the center key. A peck on the sample lit only one of the side comparison keys. If the comparison stimulus matched the sample, a peck on the comparison key produced a reinforcer. If the comparison stimulus did not

This study was supported by a faculty research grant to the first author. We would like to thank Jerry Sholl for doing the photographic work necessary to provide us with the visual stimuli employed. We also thank David Gough, Lee Goodfellow. and Richard Cross, who assisted in data collection and discussions. Reprints may be obtained from Richard Pisacreta, Department of Psychology. Ferris State College. Big Rapids, MI 49307. match the sample, and the bird did not peck the comparison key for $4.8 \mathrm{sec}$, the nonmatching comparison stimulus was terminated and the matching hue was presented on the other side key. After acquisition, transfer was obtained with two novel hues, blue and violet. Urcuioli (1977) used this procedure and reported transfer of oddity performance. Urcuioli and Nevin (1975) suggested that pigeons may fail to show transfer with the standard MTS and OFS paradigms because both procedures teach the birds a set of $S+$ rules [i.e., if green on the sample, peck green on the side key (MTS), or don't peck green on the side key (OFS)]. Neither the MTS nor the OFS procedure teaches birds a set of $S-$ rules [i.e., don't peck nonmatching stimuli (MTS), or don't peck matching stimuli (OFS)]. In related papers, Zentall and Hogan (1978), Zentall, Hogan, and Edwards (1980), and Fujita (1983) also suggested that providing negative instances (i.e., trials that provide two incorrect comparison stimuli) could improve matching transfer performance. Zentall and his colleagues suggested that transfer of OFS performance may be improved by pretraining with negative instances, possibly because negative instances may facilitate avoidance of incorrect choices and may also reduce impulsive errors.

Another way to facilitate transfer is to initially train the animals with several stimuli. Lombardi et al. (1984) trained two groups of birds to match visual patterns. One group was trained with 5 stimuli; the other group learned to match 20 stimuli. When 5 novel stimuli were later introduced, both groups showed transfer, but the group initially trained with 20 samples produced better transfer than the group that had been trained to match 5 samples. Hogan. Edwards, and Zentall (1981) reported similar results.

Recently, Pisacreta, Redwood. and Witt (1984) described a modified MTS procedure that provided several 
stimuli and negative matching conditions within each trial. The response panel employed six keys arranged in a $3 \times 2$ matrix. After the preliminary training procedures, a trial started with one of five randomly chosen samples (a drawing of a woman, bird, hand, beetle, or flower) projected on the bottom center key-the sample key. Three pecks on the sample key produced one comparison stimulus. Each additional three pecks lit another key with one more comparison stimulus, up to a maximum of five. The birds' task was to peck the sample key until the matching comparison stimulus appeared on one of the comparison keys. A peck to the matching comparison key produced grain, followed by the start of the next trial. Later, a drawing of a fish, a drawing of a rabbit, and a red hue were introduced as novel sample and comparison stimuli. The birds showed matching transfer to the new stimuli. When each new stimulus was introduced, matching accuracies did not drop to chance levels, the birds did not avoid the novel stimulus, and any matching decrement was typically eliminated within 5-10 sessions.

The present study was designed to assess whether Pisacreta et al.'s (1984) procedure would also facilitate OFS transfer performance. In addition to using an oddity task instead of a MTS procedure, the present study differed from Pisacreta et al.'s (1984) experiment in two other ways. First, color pictures of birds, butterflies, and human faces were used as sample and comparison stimuli. Because complex black-and-white stimuli (alphabet letters), as well as chromatic and achromatic slides of people, trees, and bodies of water, have been used in previous discrimination tasks (e.g., Blough, 1982; Herrnstein, 1979), we felt that complex color stimuli would serve well in the present study. Second, sets of novel stimuli replaced familiar stimuli during each phase of the experiment. Zentall and Hogan (1978) and others have suggested that transfer tests that present novel samples with familiar stimuli serving as incorrect comparison stimuli may bias the test against transfer. The birds may choose incorrect comparison stimuli because they associate them with reinforcement, a connection not yet applied to the novel sample. By totally replacing familiar stimuli with novel stimuli during each transfer phase, we avoided this potential problem.

Finally, savings in learning new OFS problems, and little deficit in accuracy levels, could be interpreted as evidence for a generalized OFS matching concept.

\section{METHOD}

\section{Subjects}

Two White Carneaux pigeons, maintained at $80 \% \pm 15 \mathrm{~g}$ of their free-feeding weights, were used. The birds had been used in a previous discrimination experiment in which they were trained to peck red hues $(S+)$ and not to peck simultaneously available green hues (S-); therefore, they had not been exposed to the stimuli or conditional discrimination contingencies used in the present study.

\section{Apparatus}

The apparatus was a $35 \times 35 \times 37 \mathrm{~cm}$ operant chamber enclosed in a sound-attenuating hull. Figure 1 shows the response panel. The $37 \times 35 \mathrm{~cm}$ response panel had eleven $2.7-\mathrm{cm}$ response keys

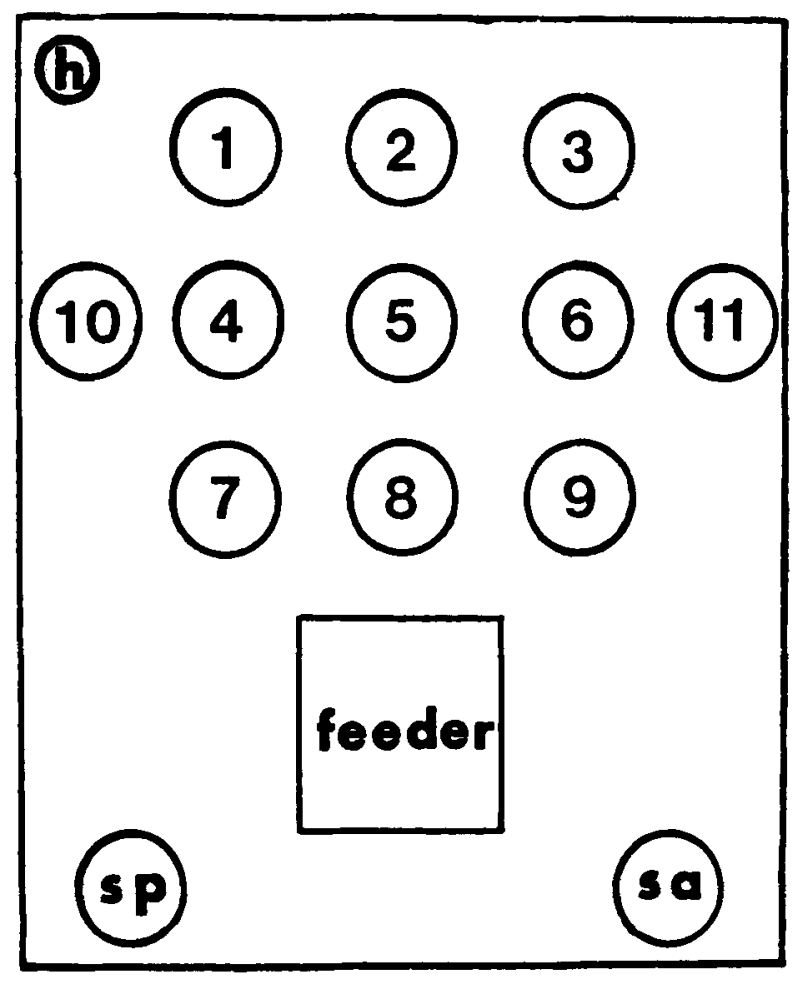

Figure 1. The response panel. Keys are numbered 1 to 11. $\mathrm{h}=$ houselight, $\mathrm{sa}=$ sonoalert, and $\mathrm{sp}=$ speaker.

(BRS/LVE Model 121-16). Stimuli were rear-projected onto the keys by means of Industrial Electronics Engineers in-line projectors (Model 1813-1820). Because the projectors could house only 12 stimuli, the film strips within them (represented in Figures 2, 3 , and 4) had to be changed three times during the study. The operating force of each key was approximately $0.16 \mathrm{~N}$. The horizontal and vertical distances between the keys were 8.1 and $6.4 \mathrm{~cm}$, respectively, center to center. A $6 \times 6 \mathrm{~cm}$ feeder aperture was centered on the wall $10 \mathrm{~cm}$ above the floor.

The feeder (BRS/LVE Model 114-10) provided 3-sec access to grain. The houselight, a GE 1820 lamp, provided light before and after daily experimental sessions. During sessions, illumination was provided only by the in-line projectors. Response keys 7, 8, 9, 10, and 11 were never illuminated. A ventilation fan and white noise delivered through the speaker masked extraneous noises. An E\&L Instruments MMD-1 computer and additional hardware recorded data and controlled experimental events.

\section{Procedure}

Table 1 summarizes the experiment. Essentially, the birds were taught to perform the OFS task with consecutive sets of stimuli. A new set of stimuli was introduced after three consecutive sessions in which the birds had produced no evidence of further improvement in performance.

Phase 1: Acquisition. Figure 2 shows the stimuli employed during Phases 1-7. The preliminary training procedures were similar to those employed by Pisacreta et al. (1984). The subjects were trained initially to the odd stimuli of the three bird photographs 1 , 2 , and 3 (Bird Set 1). At trial onset, key 5 (the sample key) presented one of these stimuli, randomly chosen. A peck on the sample key lit key 1 with a comparison stimulus. The next peck on the sample key illuminated key 3 with the second comparison stimulus. Additional pecks on the sample key had no programmed consequence. In order to produce a reinforcer, the bird had to peck the sample until the nonmatching comparison stimulus appeared on key 1 or key 3 . A peck to the nonmatching bird stimulus produced a rein- 
Table 1

\begin{tabular}{ccccc}
\multicolumn{5}{c}{ Summary of Conditions } \\
\hline Phase & $\begin{array}{c}\text { Number of } \\
\text { Comparison } \\
\text { Keys }\end{array}$ & Figure & \multicolumn{1}{c}{ Stimuli Numbers } & Sessions \\
\hline 1 & 2 & 2 & Birds 1-2-3 & 55 \\
2 & 3 & 2 & Birds 1-2-3 & 80 \\
3 & 4 & 2 & Birds 1-2-3 & 65 \\
4 & 5 & 2 & Birds 1-2-3 & 50 \\
5 & 5 & 2 & Birds 4-5-6 & 25 \\
6 & 5 & 2 & Birds 7-8-9 & 30 \\
7 & 5 & 2 & Birds 10-11-12 & 45 \\
8 & 5 & 3 & Butterflies 7-9-10 & 30 \\
9 & 5 & 3 & Butterflies 3-4-8 & $55-75$ \\
10 & 5 & 4 & Faces 2-6-7 & 30 \\
11 & 5 & 4 & Birds 5-11-12 & $25-30$ \\
12 & 5 & 4 & Butterflies 3-4-8 & 20 \\
\hline
\end{tabular}

Note-See Figures 2, 3, and 4 for stimuli numbers.

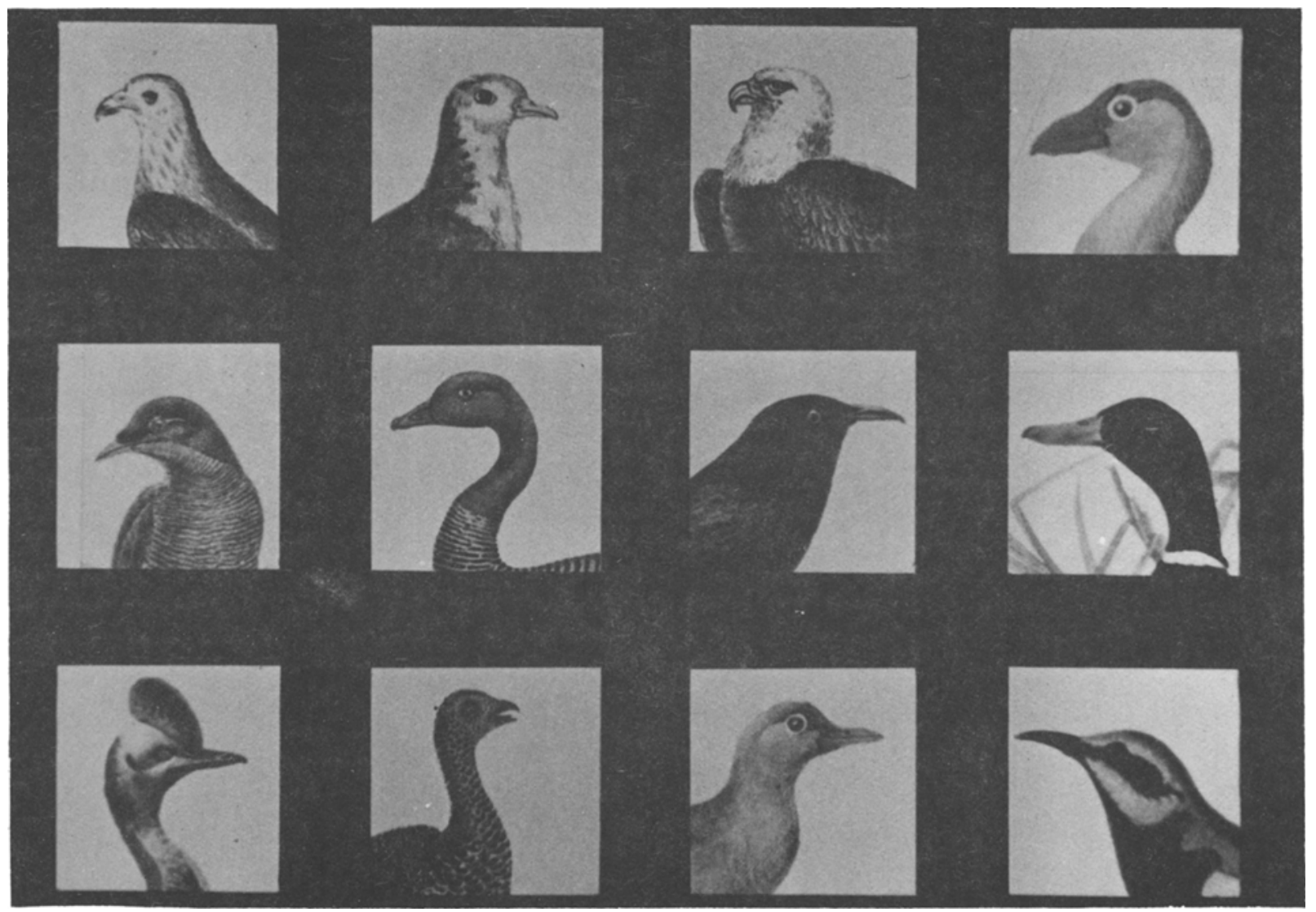

For reference (see Table 1), stimuli are numbered from top to bottom, right to left, as follows:

$\begin{array}{llll}10 & 7 & 4 & 1 \\ 11 & 8 & 5 & 2 \\ 12 & 9 & 6 & 3\end{array}$

Figure 2. Stimuli employed during Phases 1-7. (From World Treasury of Birds in Color by C. Madsen, 1974, Geneva: Editions Minerva. Copyright 1974 by Editions Minerva. Reprinted by permission.) 
forcer, a 3-sec intertrial interval, and then the next trial. An error-a peck to a matching comparison stimulus-eliminated the comparison stimuli and repeated the same trial. This "correction procedure," a repetition of the same sample and the same sequence of comparison stimuli until the bird pecked the nonmatching comparison stimulus, was in effect throughout the experiment. Sessions ended after 30 reinforcers were produced. After 25 sessions, two pecks on the sample key (a fixed ratio 2 , or FR2) were required before a comparison stimulus was provided. Thus, two pecks on key 5 lit key 1 , and two additional pecks on key 5 illuminated key 3 with the second comparison stimulus. After 15 sessions, the sample ratio requirement was raised to FR3 for the next 15 sessions. The birds were trained daily (except weekends), with two or three consecutive sessions per day.

Phase 2: Three comparison stimuli. The FR3 sample schedule was in effect for the rest of the study. Three pecks on the sample lit key 1 , as before. The sixth sample peck illuminated key 2 with the second comparison stimulus. Three more pecks produced the third comparison stimulus on key 3 . Therefore, each of the 80 sessions of this phase provided the three bird stimuli (Bird Set 1) as samples, and each stimulus was potentially available as a comparison stimulus during each trial.
Phase 3: Four comparison stimuli. Key 4 was introduced as a comparison key. Pecks on the sample (viz., 3, 6, 9, or 12 pecks) illuminated comparison keys $4,1,2$, and 3 , in that order. Phase 3 lasted 65 sessions.

Phase 4: Five comparison stimuli. Key 6 was available as a comparison key. Pecks on the sample key (viz., 3, 6, 9, 12, or 15 pecks) sequentially produced comparison stimuli on keys 6,4 , 1,2 , and 3 , in that order. Phase 4 lasted 50 sessions.

Phase 5: Three novel stimuli (Bird Set 2). Novel stimuli were stimuli that had not been presented during earlier phases. During the 25 sessions of Phase 5, bird stimuli 1,2, and 3 were replaced with bird stimuli 4, 5, and 6 . All other conditions remained the same.

Phases 6 and 7: Additional novel stimuli (Bird Sets 3 and 4). Bird stimuli 7, 8, and 9 (Bird Set 3) were presented as samples and comparison stimuli during the 30 sessions of Phase 6 ; bird stimuli 10,11 , and 12 (Bird Set 4) were employed during the 45 sessions of Phase 7.

Phases 8 and 9: Novel class of stimuli (Butterfly Sets 1 and 2). Figure 3 shows the stimuli employed during Phases 8 and 9. During Phase 8, which lasted 30 sessions, butterflies 7, 9, and 10 (Butterfly Set 1) were presented for OFS training; butterflies 3, 4, and 8 (Butterfly Set 2 ) served as samples and comparison stimuli dur-

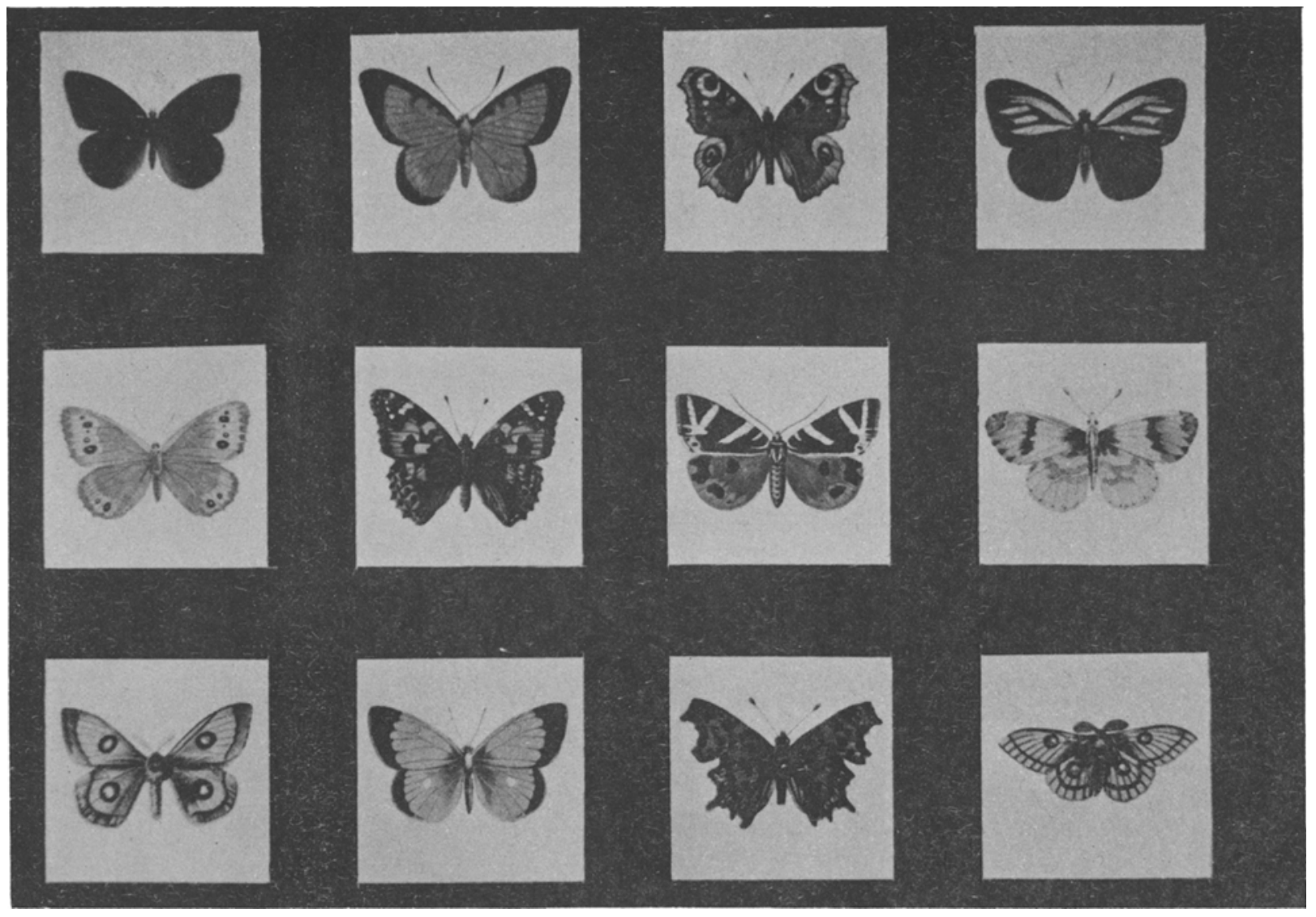

For reference (see Table 1), stimuli are numbered from top to bottom, right to left, as follows:

$\begin{array}{llll}10 & 7 & 4 & 1 \\ 11 & 8 & 5 & 2 \\ 12 & 9 & 6 & 3\end{array}$

Figure 3. Stimuli employed during Phases 8 and 9. (From World Treasury of Butterflies in Color by G. Gozzi, 1974, Geneva: Editions Minerva. Copyright 1974 by Editions Minerva. Reprinted by permission.) 
ing Phase 9. Phase 9 lasted 55 sessions for Bird B1 and 75 sessions for Bird B2.

Phase 10: Human faces. Figure 4 shows the stimuli employed during Phases 10-12. During the 30 sessions of Phase 10 , face stimuli 2, 6, and 7 were presented in the OFS paradigm.

Phase 11: Novel stimuli (Bird Set 5). Bird stimuli 5, 11, and 12 (see Figure 4) were presented during the 25-30 sessions of Phase 11.

Phase 12: Novel stimuli (Butterfly Set 3). During the 20 sessions of Phase 12, butterfly stimuli 3, 4, and 8 (see Figure 4) were employed as samples and comparison stimuli. Additionally, although 15 pecks on the sample key still illuminated the five comparison keys, the correct comparison stimulus always appeared on comparison key 6,4 , or 1 (i.e., one of the first three comparison keys to be lit).

\section{RESULTS}

Figure 5 shows the percentage of the 30 reinforced trials in which the first peck on a comparison key was correct, that is, a response to a nonmatching comparison stimulus, in Phases 1-4. Each bird performed at chance levels (50\%) during Phase 1. Similar to the results reported by Pisacreta et al. (1984), both birds frequently pecked the sample, then key 1 . If pecking key 1 was an error, the birds then pecked the sample twice and then pecked key 3 . Hence, they produced $50 \%$ (chance) oddity performance accuracies throughout Phase 1. Introduction of the third comparison key in Phase 2 produced improved OFS performances in both birds, although chance performance levels were now reduced to $33 \%$. Introduction of the fourth and fifth comparison keys in Phases 3 and 4, respectively, yielded an initial decrease in OFS accuracy levels, followed by improvement. Curiously, the accuracy levels produced at the end of each phase were higher than those in the preceding phase, although opportunities for error increased with the addition of each new comparison key. By the end of Phase 4, Birds B1 and B2 were perform-

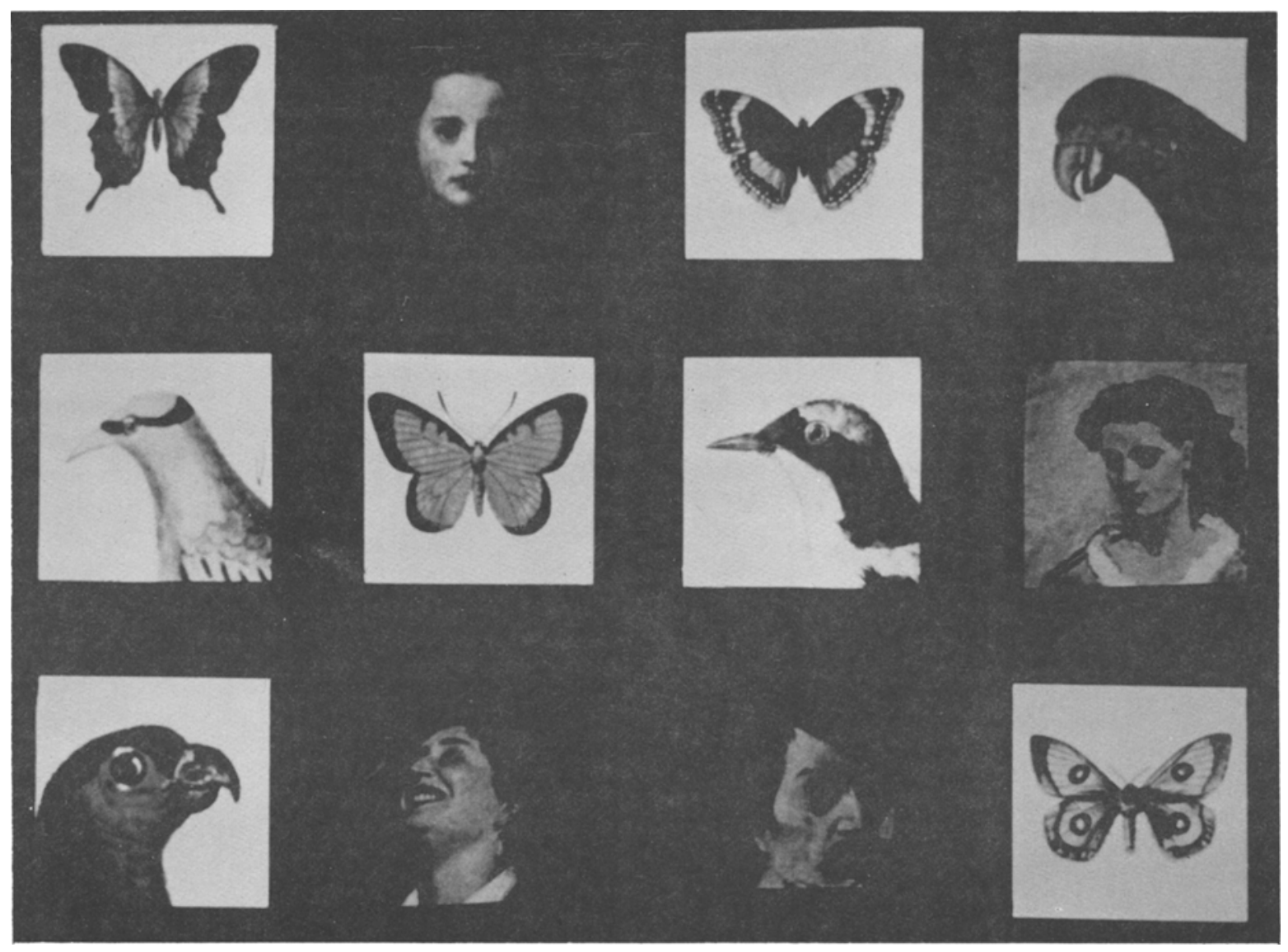

For reference (see Table 1), stimuli are numbered from top to bottom, right to left, as follows:

$\begin{array}{llll}10 & 7 & 4 & 1 \\ 11 & 8 & 5 & 2 \\ 12 & 9 & 6 & 3\end{array}$

Figure 4. Stimuli employed during Phases 10-12. (Birds from World Treasury of Birds in Color by C. Madsen, 1974, Geneva: Editions Minerva. Copyright 1974 by Editions Minerva. Butterflies from World Treasury of Butterflies in Color by G. Gozzi, 1974, Geneva: Editions Minerva. Copyright 1974 by Editions Minerva. Reprinted by permission.) 


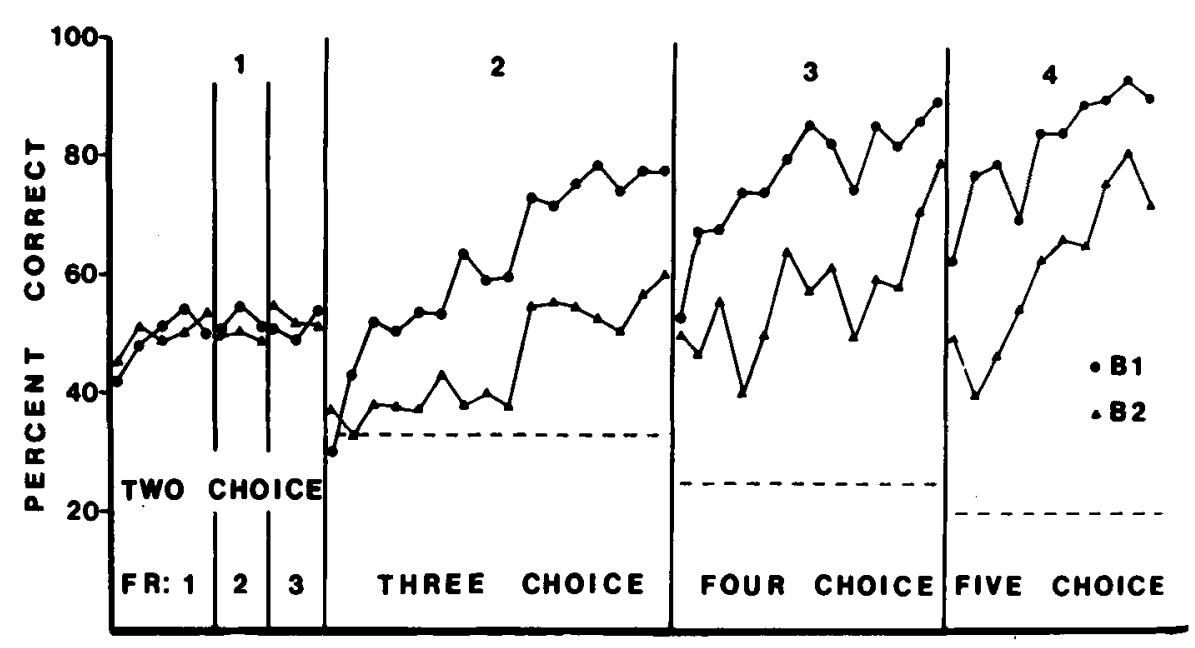

\section{BLOCKS OF FIVE}

Figure 5. Percentage of the 30 reinforced trials during Phases 1-4 in which the first peck on a comparison key was to a stimulus that did not match the sample stimulus. Each data point represents a mean taken over five consecutive sessions. FR refers to the sample-key ratio; CHOICE denotes the number of comparison stimuli available. Dotted lines represent chance performance $(50 \%, 33 \%$, $25 \%$, and $20 \%$ in Phases $1,2,3$, and 4 , respectively).

ing the oddity task without error on approximately $90 \%$ and $71 \%$ of the trials, respectively (chance $=20 \%$ ). These OFS performance levels are comparable to the $80 \%-90 \%$ accuracy levels reported by Zentall, Edwards, Moore, and Hogan (1981). No sample or comparison stimulus produced significantly more errors than any of the others.

Figure 6 presents the OFS accuracy levels maintained during Phases 5-9. The data represent the percentage of the 30 reinforced trials in which the first peck on a comparison stimulus was a correct response. Introduction of novel stimuli (Bird Sets 2, 3, and 4, respectively) in Phases 5,6 , and 7 produced a reduction of about $60 \%$ in OFS accuracy levels, followed by a recovery in performance within a few sessions. Neither bird performed below chance. Introduction of the butterfly stimuli (Butterfly Sets 1 and 2, respectively) during Phases 8 and 9 also disrupted OFS performance. The OFS accuracy levels recovered within a few sessions, even though these butterfly stimuli were harder for human (and presumably for pigeon) observers to discriminate between than

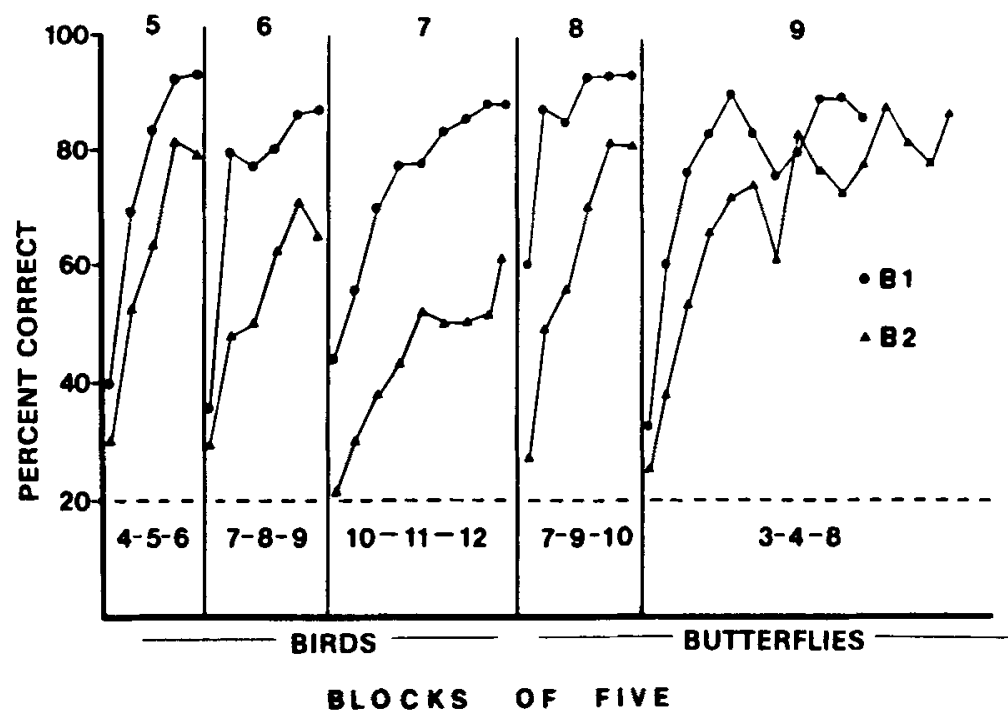

Figure 6. Matching accuracy during Phases 5-9. Number above each panel identifies the phase. The stimuli presented are identified at the bottom of each panel. Bird and butterfly stimuli are from Figures 2 and 3, respectively. Five comparison stimuli were potentially available during each trial. Chance performance (dotted line) was $20 \%$ across all phases. 
the bird photographs presented before. None of the butterfly stimuli occasioned more errors than any other butterfly sample or comparison stimulus. Bird B1 did not complete the last 20 sessions of this phase, due to a respiratory infection.

Figure 7 displays OFS accuracy levels during Phases 10-12. The data show the percentage of the 30 reinforced trials in which the first peck on a comparison stimulus was a correct response. As in earlier phases, each bird quickly learned to perform the OFS task with human faces, Bird Set 5, and Butterfly Set 3. Bird B2 performed better with the bird and butterfly stimuli than with the face stimuli, possibly due to the earlier training with these two classes of stimuli. Others have also reported better transfer when the novel stimuli are similar to the training stimuli (Zentall \& Hogan, 1978; Zentall et al., 1981). During Phase 12, the correct comparison stimulus appeared only on key 6,1 , or 2 , the first three comparison keys to light. Both birds showed less disruption of OFS performance levels during Phase 12 than during earlier phases. This is probably because the birds had prior training with butterfly stimuli and because the correct comparison stimulus was one of the first three presented.

Figure 8 shows the distribution of comparison stimulus errors (including repeated trials required by the correction procedure) across the keys during each phase. The numbers immediately above each bar represent a percentage of errors per opportunity (err/op). An err/op value was calculated by dividing the number of key errors by the number of times the key was illuminated with an incorrect comparison stimulus. Overall, the percentage of errors on a key decreased as a function of comparisonkey presentation order: that is, the highest and lowest per-

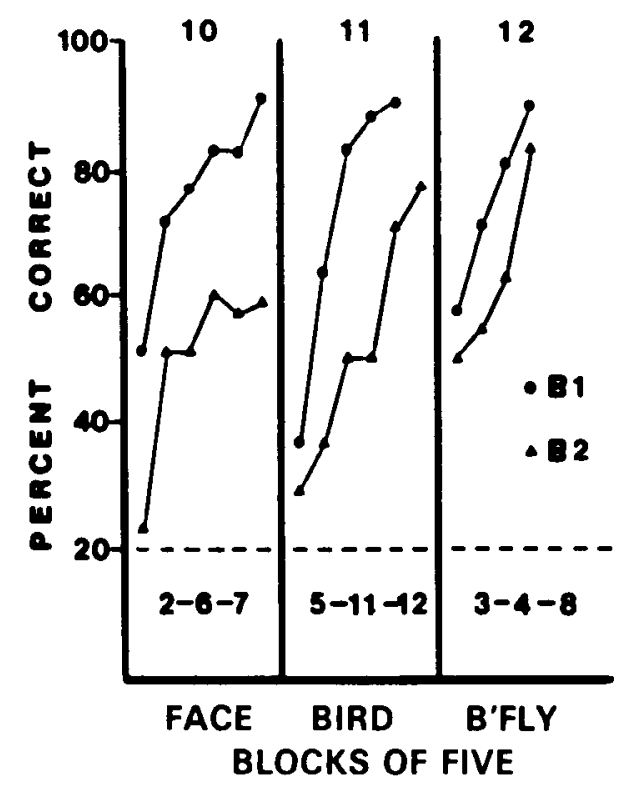

Figure 7. Matching accuracy during Phases 10-12 (phase denoted by the number above each panel). The stimuli presented are identified at the bottom of each panel; all are from Figure 4 . Chance performance (dotted line) was $20 \%$ across all phases. centage of errors were made on key 6 and key 3, respectively, with the other key error percentages falling somewhere in between these values. With the exception of key 3, the err/op percentages are comparable across the comparison keys. The err/op values $(94 \%-100 \%)$ generated on key 3 during Phases 1-3 deserve further comment. During Phase 1 (with two comparison stimuli potentially available), the birds could make an error on key 3 only by lighting key 1 with the correct comparison stimulus first, then ignoring key 1 , pecking the sample key until key 3 lit, and then pecking key 3 . Casual observation of the equipment suggested that this sequence of events often occurred when key 3 was the correct key to peck during the immediately preceding trial. Despite the err/op value generated, errors made to key 3 were few relative to total errors for Phase 1. For example, Bird B1 did not peck the correct comparison stimulus present on key 1 and lit key 3 during 116 trials of Phase 1 . It then pecked key 3109 times out of these 116 opportunities, producing a $94 \%$ err/op value. But these errors on key 3 represent only $5 \%$ of the cumulative errors made during the 55 sessions of Phase 1 . Also, 53 of these errors to key $3(48.6 \%)$ occurred during the first four sessions of the study. In subsequent sessions, the bird averaged one key-3 error per session. Similarly, the $100 \%$ err/op value produced by Bird B1 during Phase 3 represents 166 trials ( $21.8 \%$ of the cumulative errors) in which the bird lit and pecked key 3 when the correct comparison stimulus was already present on another key. In general, the err/op values generated on key 3 during Phases 1-4 decreased as training progressed. Both subjects made few pecks (less than $0.04 \%$ of the total errors made by both birds) to keys 2 and 3 during Phase 12, in which the correct comparison stimulus always appeared on key 6,4 , or 1 .

Figure 9 shows error distributions (including repeated trials required by the correction procedure) as a function of the key on which the nonmatching comparison stimulus was presented. In general, errors tended to increase as a function of the number of comparison keys that had to be lit before the nonmatching comparison stimulus was available. When the first comparison key to light was programmed to present the nonmatching comparison stimulus, the bird could make an error only by ignoring this key. However, when the fifth comparison key to light presented the correct comparison stimulus to peck during that trial, the bird had to first produce and ignore four other comparison stimuli. Hence, the more comparison stimuli available before the nonmatching comparison stimulus appeared, the greater the number of opportunities to make an error. Pisacreta et al. (1984) reported similar results.

Table 2 shows a comparison of the errors produced during the last nine sessions of each phase and errors made during the first nine sessions of the subsequent phase. The data from the earlier phase are presented in three-session blocks labeled $3,2,1$. The errors from the subsequent phase are provided in three-session blocks labeled 1, 2, 


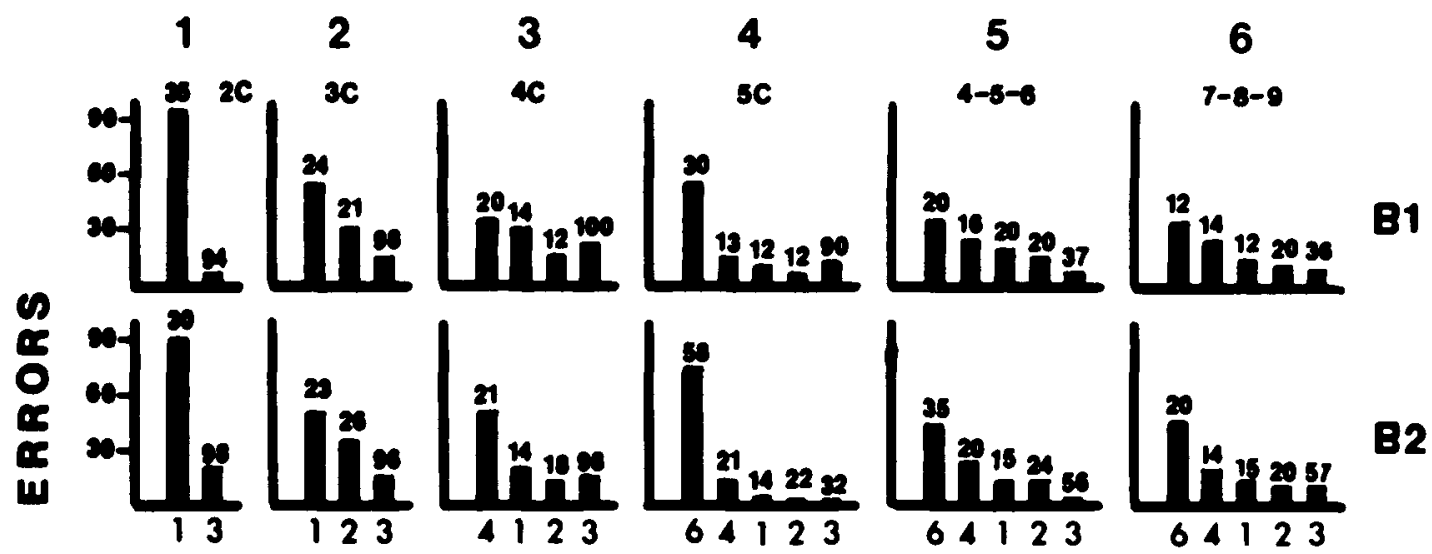

1
2
0
0
11
0

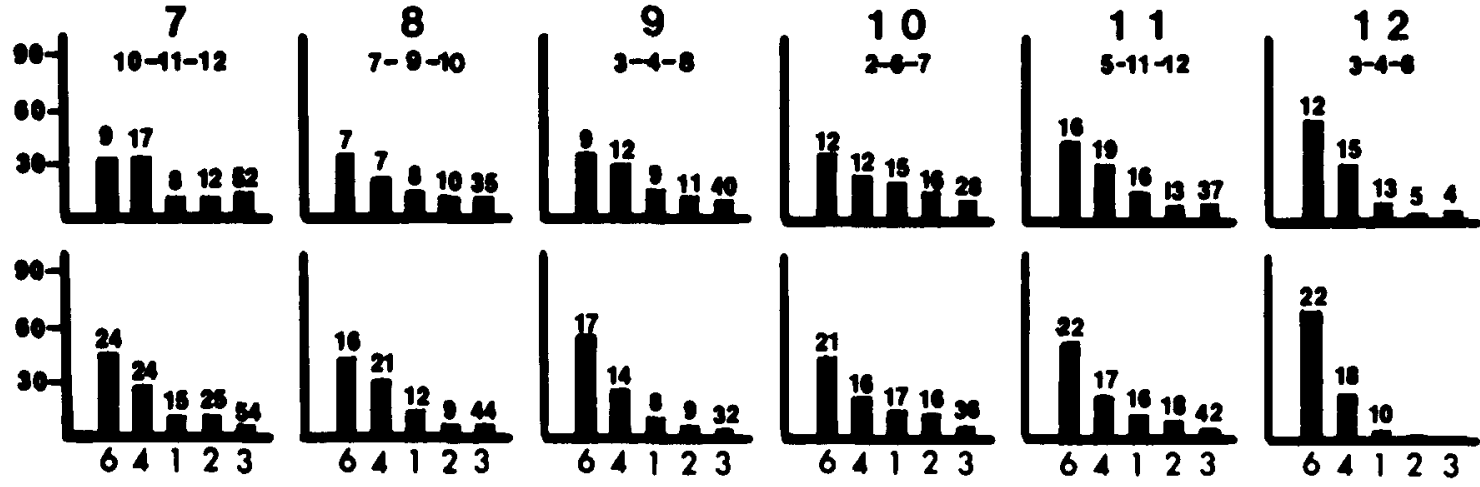

\section{K E Y S}

Figure 8. Black bars represent the percentage of errors (including correction trials) across the comparison keys during each phase. Comparison-key orders on the abscissa show the order in which sample pecks produced them. Numbers above each bar represent the percentage of errors per opportunity (cumulative errors on a comparison key divided by the number of times the key was lit with an incorrect comparison stimulus). Large number at the top of each panel indicates the phase; smaller numbers below the phase number represent the stimuli presented during the phase. $2 \mathrm{C}, 3 \mathrm{C}, 4 \mathrm{C}$, and $5 \mathrm{C}$ refer to the number of comparison stimuli (choices) available.

3. As reflected in earlier figures, Bird B1 performed reliably better than Bird B2. With the exception of Phase 2, the introduction of each additional comparison key yielded only a slight increase in errors. The transition data from Phases 4-7 show that (1) the introduction of each new set of bird stimuli produced an initial increase in errors, (2) these error levels were greatly reduced within a few sessions, (3) both birds showed less of an initial increase in error levels when exposed to each new set of bird stimuli, and (4) error levels at the end of a phase were comparable to those produced at the end of previous phases. Similar results were found during Phases 7-11, within which butterfly and face stimuli were provided. In general, both birds tended to show less of an increase in errors during the first three sessions of Phases 8,9 , 10 , and 11 than during the first three sessions of Phases 5 , 6 , and 7. This transition improvement (i.e., better transfer of OFS performance) occurred even though the stimuli were changed from birds to butterflies to faces.

The data from the initial sessions of Phase 12 (in which the correct comparison stimulus was presented only on key 6,4 , or 1 ) suggest that superior transfer occurs when the correct comparison stimulus is presented on one of three (instead of one of five) keys. Although at least three comparison keys are necessary to establish high accuracy levels with this procedure (see Phase 2; see also Pisacreta et al., 1984), the results suggest that better transfer of OFS performance might occur if the transfer tests were conducted with fewer comparison keys illuminated. Another way to improve transfer might be to illuminate the comparison keys in a random, rather than fixed, sequence. Still, the present data suggest that pigeons can exhibit, to some degree, the "learning set" described by Harlow (1949).

\section{DISCUSSION}

The present study shows that pigeons can learn (1) to show facilitated acquisition (a savings in learning) across humanly defined stimulus classes, that is, birds, butterflies, and human faces; (2) to rapidly acquire several novel sets of OFS problems; and (3) to avoid responding to keys illuminated with up to four matching comparison stimuli.

The use of complex visual stimuli in discrimination procedures may contribute to above-chance accuracy levels during transfer tasks. Poole and Lander (1971) 


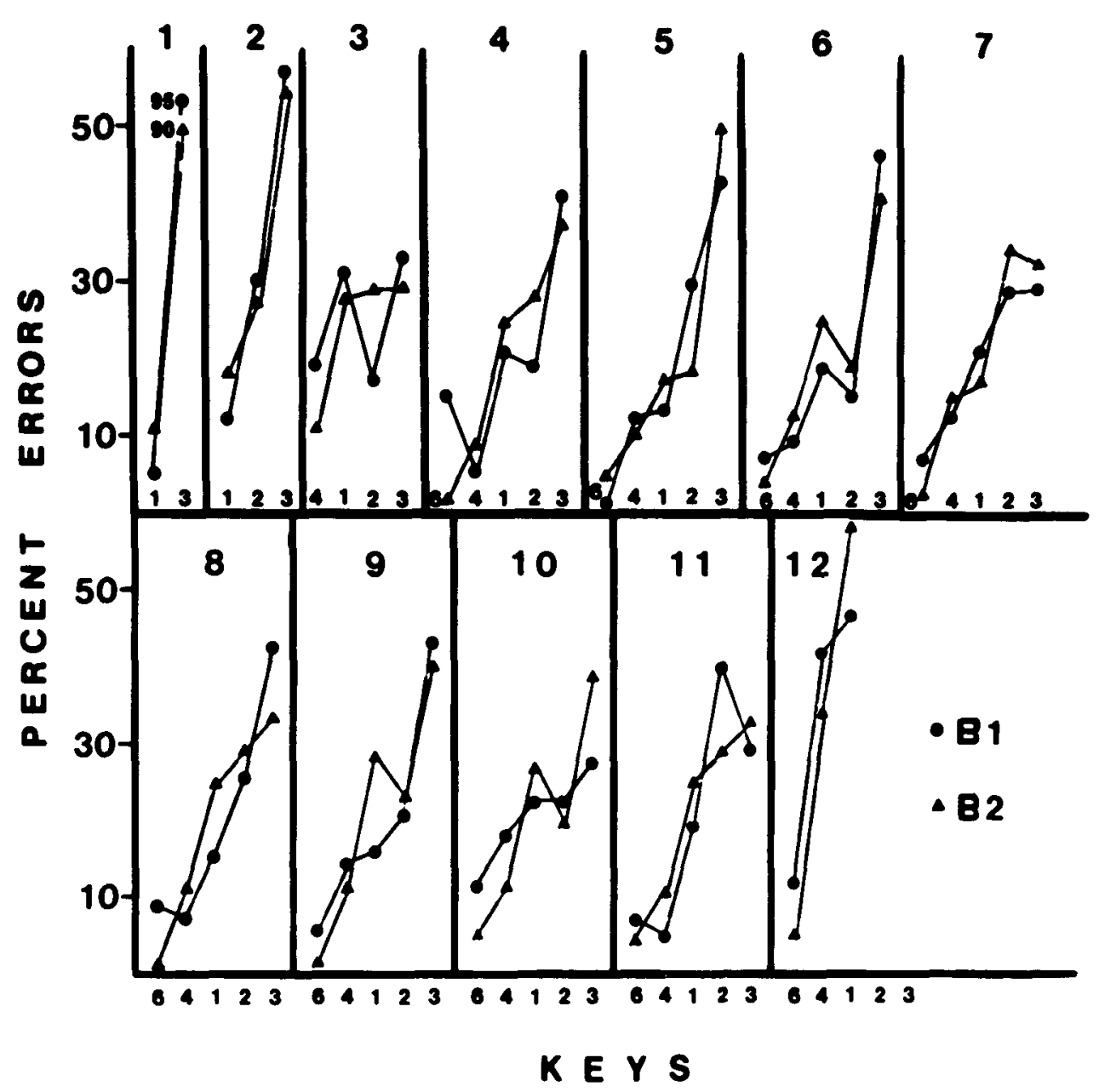

Figure 9. Error distributions (including repeated trials) as a function of correct comparison key. Numbers at the bottom of each panel represent the correct comparison key to peck and the order in which sample pecks produced them. Phase is indicated by the number above each panel. For example, during Phase 1, Bird B1 made 5\% of its errors when the correct comparison key to peck was key 1 , and $95 \%$ of its errors when the correct comparison key was key 3.

demonstrated that pigeons could learn to discriminate between pictures of different breeds of pigeons, other animals, and nonliving objects. Malott and Siddall (1972) used pictures of people, and Cerella (1979) reported that pigeons could learn to discriminate between oak leaves and could respond to 40 new stimuli without a discrimination decrement. In related studies, Herrnstein (1979) and Herrnstein, Loveland. and Cable (1976) showed that pigeons could learn to respond to pictures only if the pictures depicted trees, bodies of water, or particular people; the birds in these studies also showed transfer to novel stimuli. Our birds established and maintained $70 \%-90 \%$ oddity performance accuracy with 27 different complex stimuli. and their oddity performance levels never fell be low chance $(20 \%)$. Although others have reported that birds do poorly with transfer trials that present orthogonal stimuli (e.g., Zentall \& Hogan. 1975, 1976), our birds showed transfer of OFS performance across several sets of bird, butterfly, and face stimuli.

Several factors could have contributed to the performances reported in this study. Many reports have sug- gested that training animals with a large number of stimuli facilitates matching transfer (e.g., Holmes, 1979; Levine \& Harlow, 1959; Lombardi et al., 1984; Pisacreta \& Witt. 1983; Urcuioli \& Nevin, 1975). The frequent use in previous studies of negative-instance trial conditions (only matching stimuli available; Urcuioli, 1977; Zentall \& Hogan, 1978), and the use of only novel stimuli during matching transfer phases (Zentall \& Hogan, 1974, 1976) may also have influenced the birds' acquisition and transfer behavior. It is possible that presentation of the comparison stimuli sequentially, rather than simultaneously (as is the case in the standard OFS study), allows the pigeon to focus its attention more easily on the individual comparison stimuli. Two related papers suggest that this may be the case. Pisacreta (1982) presented pigeons with five illuminated keys. Four of the keys showed the same color (red, blue, or green), whereas the fifth key provided one of the other hues. A peck to any key changed the stimulus on that key to one of the other two colors. The bird's task was to make all five keys show the same color. Later, the number of lit keys and the num- 
Table 2

Initial Transition Errors Across Phases

\begin{tabular}{|c|c|c|c|c|c|c|c|}
\hline \multirow[b]{2}{*}{ Phases } & \multirow[b]{2}{*}{ Subject } & \multicolumn{6}{|c|}{ Session Blocks } \\
\hline & & 3 & 2 & 1 & 1 & 2 & 3 \\
\hline \multirow{3}{*}{1 to 2} & & \multicolumn{3}{|c|}{ 2-Choice } & \multicolumn{3}{|c|}{ 3-Choice } \\
\hline & B1 & 17 & 17 & 15 & 121 & 87 & 70 \\
\hline & $\mathrm{B} 2$ & 14 & 15 & 13 & 154 & 99 & 50 \\
\hline \multirow{3}{*}{2 to 3} & & \multicolumn{3}{|c|}{ 3-Choice } & \multicolumn{3}{|c|}{ 4-Choice } \\
\hline & B1 & 9 & 9 & 7 & 22 & 19 & 14 \\
\hline & B2 & 20 & 16 & 14 & 27 & 24 & 26 \\
\hline \multirow{3}{*}{3 to 4} & & \multicolumn{3}{|c|}{ 4-Choice } & \multicolumn{3}{|c|}{ 5-Choice } \\
\hline & $\mathrm{Bl}$ & 5 & 6 & 4 & 30 & 15 & 6 \\
\hline & B2 & 9 & 7 & 6 & 65 & 20 & 22 \\
\hline \multirow{3}{*}{4 to 5} & & \multicolumn{3}{|c|}{ 5-Choice } & \multicolumn{3}{|c|}{ Bird Set 2} \\
\hline & Bl & 3 & 3 & 4 & 115 & 61 & 12 \\
\hline & B2 & 6 & 6 & 7 & 133 & 30 & 19 \\
\hline \multirow{3}{*}{5 to 6} & & \multicolumn{3}{|c|}{ Bird Set 2} & \multicolumn{3}{|c|}{ Bird Set 3} \\
\hline & B1 & 2 & 4 & 2 & 92 & 32 & 6 \\
\hline & $\mathrm{B} 2$ & 6 & 8 & 8 & 131 & 60 & 25 \\
\hline \multirow{3}{*}{6 to 7} & & \multicolumn{3}{|c|}{ Bird Set 3} & \multicolumn{3}{|c|}{ Bird Set 4} \\
\hline & $\mathrm{B} 1$ & 4 & 4 & 5 & 69 & 38 & 21 \\
\hline & B2 & 11 & 10 & 10 & 117 & 79 & 62 \\
\hline \multirow{3}{*}{7 to 8} & & \multicolumn{3}{|c|}{ Bird Set 4} & \multicolumn{3}{|c|}{ Butterfly Set 1} \\
\hline & B1 & 6 & 2 & 4 & 44 & 14 & 3 \\
\hline & $\mathrm{B} 2$ & 18 & 18 & 12 & 72 & 38 & 18 \\
\hline \multirow{3}{*}{8 to 9} & & \multicolumn{3}{|c|}{ Butterfly Set 1} & \multicolumn{3}{|c|}{ Butterfly Set 2} \\
\hline & $\mathrm{B} 1$ & 2 & 4 & 2 & 65 & 41 & 19 \\
\hline & $\mathrm{B} 2$ & 5 & 4 & 7 & 99 & 64 & 28 \\
\hline \multirow{3}{*}{9 to 10} & & But & rfly & 2 & & ace & \\
\hline & B1 & 2 & 6 & 4 & 67 & 46 & 15 \\
\hline & $\mathrm{B} 2$ & 7 & 4 & 6 & 91 & 58 & 26 \\
\hline & & & ace & & & $\mathrm{Se}$ & \\
\hline 10 to 11 & B1 & 6 & 5 & 2 & 86 & 32 & 19 \\
\hline & $\mathrm{B} 2$ & 20 & 22 & 17 & 105 & 45 & 37 \\
\hline & & & $\mathrm{d} S \mathrm{se}$ & & Butt & fly & 3 \\
\hline 11 to 12 & $\mathrm{Bl}$ & 5 & 5 & 5 & 24 & 13 & 10 \\
\hline & $\mathrm{B} 2$ & 10 & 7 & 8 & 23 & 18 & 16 \\
\hline
\end{tabular}

Note-Data show mean errors made to comparison stimuli in threesession blocks during the last nine sessions $(3,2,1)$ of a phase and during the first nine sessions $(1,2,3)$ of the subsequent phase.

ber of stimuli available on them were manipulated. The most efficient strategy was to peck only the nonmatching key, until it matched the other four. This procedure can be considered a case of oddity learning with all five comparison stimuli simultaneously available. The birds matched efficiently (i.e., produced a match with the fewest keypecks possible) during $20 \%-80 \%$ of the session trials across phases. In a follow-up study, Pisacreta and Witt (1983) also employed four matching keys and one odd key at trial onset; in this study, however, pecks to the matching keys had no consequence. The birds had to peck the nonmatching key in order to produce a reinforcer. The birds produced only $40 \%-60 \%$ matching accuracy, even with as few as three lit keys. Requiring the birds to peck a sample key at trial onset improved accuracy levels by $7 \%-20 \%$. The data suggest that whether stimuli are presented simultaneously or sequentially may be an important factor in the acquisition and maintenance of conditional discriminations.

In their review article, Carter and Werner (1978) discussed three explanations for matching behavior: (1) the configuration model, which claims that animals learn a set of discriminations; (2) the multiple-rule model, which suggests that animals acquire a set of two-component chains; that is, they learn a series of "if-then" behaviors, for example, "if Bird 1 is on key 5, then peck Bird 2 or 3 on key 1,2, 3, 4, or 6"; and (3) the single-rule model, which proposes that nonhumans learn an oddity concept. The configuration model, which explains oddity performance as a case of three-key (or five-key, in the present case) discrimination, seems inapplicable to the present study. The pigeons would have had to acquire over 300 different discriminations across the 12 phases of the study. The multiple-rule (two-component-chain) model can undoubtedly be applied to any situation in which the animals make errors during transfer tests. However, the speed of acquisition and the above-chance OFS performances across phases in the present study lead us to believe that the birds were operating to some extent under a single rule: "peck the sample key until a nonmatching comparison stimulus appears" (a rudimentary concept of oddity). Harlow (1949) defined "learning set," or learning to learn, as the ability to show a savings in time or trials in learning new problems after having mastered similar problems. Our study produced some evidence that the birds were indeed learning to perform the oddity task regardless of the stimuli presented.

Premack (1978) suggested that pigeons cannot produce effective transfer data because they cannot make true same-different judgments, respond to relational rather than absolute stimulus factors, or extrapolate to orthogonal stimuli. Conceptual-type learning may also be in evidence if the birds need less time or fewer trials when acquiring new matching problems. Premack later added (1983) that, among animals, only language-trained chimpanzees can acquire the concept of same-different discriminations. Premack pointed out that pigeons fail to produce impressive evidence of concept learning within the standard MTS and OFS paradigms unless the procedures are modified (e.g., Malott \& Malott, 1970; Urcuioli, 1977; Urcuioli \& Nevin, 1975).

Our results, as well as those reported in related studies (e.g., Fujita, 1983; Malott \& Malott, 1970; Pisacreta et al., 1984; Pisacreta \& Witt, 1983; Zentall \& Hogan, 1978), suggest that, under some modified matching conditions, pigeons can indeed learn the concept of samedifferent. Furthermore, the birds in the present study had to satisfy each of Premack's other criticisms in order to perform as well as they did. Many other critics of the pigeon's ability to demonstrate rudimentary abstract-type learning also base their views on data generated with the 
standard three-key MTS and OFS conditional discrimination procedures (e.g., Carter \& Eckerman, 1976; Carter \& Werner, 1978; Farthing \& Opuda, 1974).

Perhaps the MTS and OFS procedures are the wrong paradigms to use when attempting to measure conceptualtype learning ability in animals. In these procedures, pigeons are typically trained with two or three matching or oddity problems and then tested with one or two novel samples. When the birds fail to show transfer, it is suggested that a matching or oddity concept is beyond the pigeon's ability. However, if three-key discriminations or two-component chains reliably yield reinforcement, why should the pigeon learn a generalized matching or oddity rule? Schwartz (1982) pointed out that conceptualtype learning requires variability from trial to trial, whereas reinforcement tends to produce repetition that may actually inhibit learning. Schwartz showed that even humans have difficulty learning rules if simple repetition is all that is required to reliably produce reinforcers. Perhaps reinforcing hundreds or thousands of trials that offer one of three samples to the pigeon may actually reduce the likelihood of matching transfer. This speculation may help explain the conflicting reports concerning animal cognition. How can the pigeon fail to show transfer with a novel hue or form in one study and yet show transfer from a photograph of a puddle of water to a photograph of an ocean in another study? The typical experiment that employs a delayed MTS or OFS procedure reports recall decay after a few seconds or minutes. Yet Shettleworth (1983) demonstrated that birds can store seeds and retrieve them several months later.

We are becoming convinced that the three-key MTS and OFS paradigms, using hue or form stimuli, may be the wrong procedures to employ for the purpose of providing evidence of conceptual-type learning and mediated transfer. Conceptual behavior is intrinsically complex and may require complex learning conditions beyond those required by the standard MTS and OFS procedures. On the basis of recent studies (see Roitblat, Bever, \& Terrace, 1984), we suggest that the likelihood of producing conceptual-type behavior in nonhumans may be increased if researchers develop procedures that: (1) employ a large number of stimuli, presented in numerous spatial arrays; (2) use complex stimuli (pictures, drawings, photographs, etc.) instead of simple hues or forms, because complex stimuli may require attention to stimulus detail, which in turn facilitates conceptual-type learning; (3) provide negative instances (stimulus conditions within which reinforcement is unobtainable); (4) present several concurrent response choices (pecking keys, levers, maze choice points, etc.): (5) introduce several novel stimuli simultaneously; (6) employ a response-cost-for-errors contingency (i.e., repeat the trial, timeout, etc.); and (7) provide contingencies that require the animal to learn a rule in order to reliably produce reinforcers.

It may be that conceptual-type behaviors can be produced only by complex procedures. Simple learning tasks with slight variability, that is, one or two novel stimuli introduced late in training, may fail to produce transfer because the procedure requires the animals to form associations only between the training stimuli and their behavior. Failure to show transfer to the novel stimuli appears to suggest that the animal can learn only discrete stimulus-response behavioral chains. This may be an erroneous conclusion. It is possible that to some extent the disparity in reports assessing animal capabilities reflects faults inherent in our procedures, rather than in our subjects.

\section{REFERENCES}

Berryman, R., Cumming, W. W., Cohen, L. R., \& Johnson, D. F. (1965). Acquisition and transfer of simultaneous oddity. Psychological Reports, 17, 767-775.

BLough, D. S. (1982). Pigeon perception of letters of the alphabet Science, 218, 397-398.

Carter, D. E., \& Eckerman, D. A. (1976). Reply to Zentall and Hogan. Science, 191, 409

CARTER, D. E., \& Werner, T. J. (1978). Complex learning and information processing by pigeons: A critical analysis. Journal of the $E x-$ perimental Analysis of Behavior, 29, 565-601.

Cerella, J. (1979). Visual classes and natural categories in the pigeon. Journal of Experimental Psychology: Human Perception \& Performance, 5, 68-77.

FaRTHING, G. W., \& OpUda, M. J. (1974). Transfer of matching-tosample in pigeons. Journal of the Experimental Analysis of Behavior, 21, 199-213.

Fujit A, K. (1983). Acquisition and transfer of a higher-order conditional discrimination performance in the Japanese monkey. Japanese Psychological Research, 25, 1-8.

GozzI, G. (1974). World treasury of butterflies in color (D. Macrae, Trans.). Geneva: Editions Minerva.

HarLow, H. F. (1949). The formation of learning sets. Psychological Review, 56, 51-65.

HerRnStein, R. J. (1979). Acquisition, generalization, and discrimination reversal of a natural concept. Journal of Experimental Psychology: Animal Behavior Processes, 5, 116-129.

Herrnstein, R. J., Loveland, D. H., \& Cable, C. (1976). Natural concepts in pigeons. Journal of Experimental Psychology: Animal Behavior Processes, 2, 285-302.

Hogan, D. E., Edwards, C. A., \& Zentall, T. R. (1981). The role of identity in the learning and memory of matching-to-sample by pigeons. Bird Behavior, 3, 27-36.

HoLMES, P. W. (1979). Transfer of matching performance in pigeons. Journal of the Experimental Analysis of Behavior, 31, 103-114.

Levine, M., \& HaRlow, H. F. (1959). Learning-sets with one- and twelve-trial oddity-problems. American Journal of Psychology, 72, 253-257

Lombardi, C. M., Fachinelli, C. C., \& Delius, J. D. (1984). Oddity of visual patterns conceptualized by pigeons. Animal Learning \& Behavior, 12, 2-6.

MACKINTOSH, N. J. (1983). Conditioning and associative learning. Oxford: Clarendon.

MACPHAIL, E. (1982). Brain and intelligence in vertebrates. Oxford: Clarendon.

MADSEN. C. (1974). World treasury of birds in color (D. Macrae, Trans.). Geneva: Editions Minerva.

Malott, R. W., \& Malott, M. K. (1970). Perception and stimulus generalization. In W. C. Stebbins (Ed.), Animal psychophysics: The design and conduct of sensory experiments (pp. 363-400). New York: Appleton-Century-Crofts

MalotT, R. W., \& SidDall, J. W. (1972). Acquisition of the people concept in pigeons. Psychological Reports, 31, 3-13.

Pisacreta, R. (1982). Preferences among stimulus matches in the pigeon. Journal of the Experimental Analysis of Behavior, 38, 191-199.

Pisacreta, R., RedWood, T., \& WITT, K. (1984). Transfer of matching- 
to-figure samples in the pigeon. Journal of the Experimental Analysis of Behavior, 42, 223-237.

Pisacreta, R., \& Witt, K. (1983). Same-different discriminations in the pigeon. Bulletin of the Psychonomic Society, 21, 411-414.

Poole, J., \& LANDER, D. G. (1971). The pigeon's concept of people. Psychonomic Science, 25, 157-158.

Premack, D. (1978). On the abstractness of human concepts: Why it would be difficult to talk to a pigeon. In S. H. Hulse, H. Fowler, \& W. K. Honig (Eds.), Cognitive processes in animal behavior (pp. 423-451). Hillsdale, NJ: Erlbaum.

Premack, D. (1983). The codes of beast and man. The Behavioral \& Brain Sciences, 6, 125-167.

Roitblat, H. L., Bever, T. G., \& Terrace, H. S. (EDs.) (1984). Animal cognition. Hillsdale, NJ: Erlbaum.

ScHWARTZ, B. (1982). Reinforcement-induced behavioral stereotypy: How not to teach people to discover rules. Journal of Experimental Psychology: General, 111, 23-59.

Shettleworth, S. J. (1983). Memory in food hoarding birds. Scientific American, 248, 102-110.

URCUIOLI, P. J. (1977). Transfer of oddity-from-sample performance in pigeons. Journal of the Experimental Analysis of Behavior, 27, 195-202.

URCuIOLI, P. J., \& Nevin, J. A. (1975). Transfer of hue matching in pigeons. Journal of the Experimental Analysis of Behavior, 24, 149-155.

Zentall, T. R., Edwards, C. A., Moore, B. S., \& Hogan, D. E.
(1981). Identity: The basis for both matching and oddity learning in pigeons. Journal of Experimental Psychology: Animal Behavior Processes, 7, 70-86.

Zentall, T. R., \& Hogan, D. E. (1974). Abstract concept learning in the pigeon. Journal of Experimental Psychology, 88, 393-398.

Zentall, T. R., \& Hogan, D. E. (1975). Concept learning in the pigeon: Transfer to new matching and non-matching stimuli. American Journal of Psychology, 88, 233-244.

Zentall, T. R., \& Hogan, D. E. (1976). Pigeons can learn identity or difference. Science, 191, 408-409.

Zentall, T. R., \& Hogan, D. E. (1978). Same/different concept learning in the pigeon: The effect of negative instances and prior adaption to transfer stimuli. Journal of the Experimental Analysis of Behavior, 30, 177-186.

Zentall, T. R., Hogan, D. E., \& Edwards, C. A. (1980). Oddity learning in the pigeon: Effect of negative instances, correction, and number of incorrect alternatives. Animal Learning \& Behavior, 8 , 621-629.

Zentall, T. R., Hogan, D. E., Edwards, C. A., \& Hearst, E. (1980). Oddity learning in the pigeon as a function of the number of incorrect alternatives. Journal of Experimental Psychology: Animal Behavior Processes, 6, 278-299.

(Manuscript received January 23, 1985; revision accepted for publication May 3, 1985.) 